\title{
The Adult Rat Olfactory System Expresses Microtubule-Associated Proteins Found in the Developing Brain
}

\author{
Christopher Viereck, Richard P. Tucker, ${ }^{\mathrm{a}}$ and Andrew Matus \\ Friedrich Miescher-Institut, $\mathrm{CH}-4002$ Basel, Switzerland
}

\begin{abstract}
We have compared the expression and localization of neuronal microtubule-associated proteins (MAPs) MAP5, MAP2, and tau in the adult rat olfactory system and cerebral cortex. Each of these MAPS is known to exist as distinct "early" and "late" forms in the developing and adult brain, respectively. Because axonal growth and dendritic reinnervation continue in the adult olfactory system, it can serve as a test of whether expression of early MAP forms is necessary for neuronal growth and plasticity. We found that for all three MAPs, the early forms continue to be expressed in the adult olfactory system, whereas the cerebral cortex switches to the late forms during neuronal maturation (between 10 and 20 days of age in the rat). For MAP2, the $6 \mathrm{~kb}$ mRNA and low-molecular weight MAP2c, both of which are typically found in embryonic tissue, persist in the adult olfactory bulb. For MAP5, an early highly phosphorylated form, MAP5a, is present throughout the brain and disappears during maturation simultaneously with a several-fold drop in the overall level of MAP5. However, in the olfactory bulb, MAP5 levels do not fall, and MAP5a persists in the adult. The early form of tau is also prominent in the adult olfactory bulb and, by immunohistochemistry, is mainly confined to a subset of olfactory axons, the vomeronasal nerve. Thus, in the adult olfactory bulb, both MAP protein synthesis and phosphorylation conform to a pattern associated with the developing brain. Immunohistochemistry also showed that MAP5 is concentrated in the olfactory nerve axons and the mitral cell dendrites of the olfactory bulb, i.e., exactly those elements that are involved in the olfactory nerve innervation that takes place in the adult. These results suggest that the expression of the early MAP forms is closely associated with neurite outgrowth and plasticity.
\end{abstract}

Brain microtubule-associated proteins (MAPs) have been implicated in a number of events during neuronal morphogenesis, including the promotion of tubulin polymerization, the stabilization of neuronal processes, and the development and maintenance of the distinct morphologies of dendrites and axons (see

Received Oct. 17, 1988; revised Mar. 27, 1989; accepted Apr. 4, 1989

The authors wish to thank L. I. Binder for the AP14, Tau-1, and Tu27 monoclonal antibodies, G. Raisman for helpful advice and discussion, N. Papandrikopoulou, W. Halfter, and B. Brugg for reviewing this manuscript, and L. Farmer and $T$. Doll for expert assistance with the hybridoma cultures and plasmid preparations, respectively.

Correspondence should be addressed to Christopher Viereck at his present address: Merck Frosst Canada Inc., P.O. Box 1005, Pte. Claire-Dorval, Quebec, Canada H9R 4P8.

${ }^{a}$ Present address: Department of Anatomy, Bowman Gray School of Medicine, Wake Forest University, Winston-Salem, NC 27103.

Copyright (C) 1989 Society for Neuroscience $0270-6474 / 89 / 103547-11 \$ 02.00 / 0$ reviews by Nunez, 1986; Matus, 1988). Perhaps the strongest evidence that MAPs are involved in events associated with neuronal plasticity and stabilization is their developmental regulation. Distinct "early" and "late" forms of several MAP species have been described, and the change in form of expression in all cases occurs at precisely the time when axon and dendrite growth cease and more stable, mature circuitry is formed (Bernhardt et al., 1985; Riederer and Matus, 1985; Viereck et al., 1988).

In the mammalian nervous system, neurons are born and complete their differentiation in the embryo and during a brief period after birth. One exception, however, is the olfactory system, where the growth and differentiation of sensory neurons continue throughout adult life (Graziadei and Monti-Graziadei, 1979). The newly born olfactory neurons extend processes that grow into the olfactory bulb and directly contact mitral, tufted and periglomerular cell dendrites with distinct glomeruli (Pinching and Powell, 1971). These elements are thus constantly reinnervated during adult life. The adult olfactory system provides a test of whether the early MAP forms expressed in the developing brain are controlled merely chronologically or whether these proteins are necessary participants in neuronal differentiation and plasticity.

MAP5' is a 320,000 Da protein that is abundant in the developing brains of rat and quail but whose levels fall on neuronal maturation so that it is only a minor component in adult tissue (Riederer et al., 1986; Tucker and Matus, 1987; Tucker et al., 1988a). It is the first MAP to appear in extending axons, being present at high levels from their first appearance (Tucker and Matus, 1987; Tucker et al., 1988a). MAP5 is thus a very effective immunocytological marker for developing neurites. MAP2 in the developing brain consists of a single high-molecular weight component, MAP2b $(280,000 \mathrm{Da})$, that is dendrite-specific (Bernhardt and Matus, 1984; Tucker et al., 1988a) and a lowmolecular weight form, MAP2c (70,000 Da; Riederer and Matus, 1985). In adult tissue, MAP2c is present at only trace levels (Riederer and Matus, 1985), and a second high-molecular weight component, MAP2a, is present (Binder et al., 1984; Burgoyne and Cumming, 1984). Recent studies in our laboratory (Garner and Matus, 1988) have demonstrated that the low- and highmolecular weight forms of MAP2 are translated from separate mRNAs ( $6 \mathrm{~kb}$ and $9 \mathrm{~kb}$ ) that are transcribed from a single gene. During brain development, the $6 \mathrm{~kb} \mathrm{mRNA}$ is turned off concomitant with the drop in MAP2c protein. A different expression pattern has been described for the axon-specific tau poly-

\footnotetext{
Recent experiments in our laboratory (Garner et al., 1989) suggest that MAP5 is closely related to and is probably identical with the proteins named independently as MAP1x (Calvert and Anderton, 1985), MAP1.2 (Greene et al., 1983), and MAP1b (Bloom et al., 1985).
} 
peptides (Binder et al., 1985). In the developing brain, tau is present as a single $48,000 \mathrm{Da}$ form (Francon et al., 1982), whereas in adult tissue, there are at least four major tau forms of 52,00068,000 Da (Binder et al., 1985).

We report here that the adult rat olfactory bulb differs from the adult cerebral cortex in terms of the expression patterns of 3 major MAPs: MAP5, MAP2, and tau. Unlike the cerebral cortex, the adult olfactory bulb expresses the early forms of these cytoskeletal proteins. These results, as well as those obtained from our immunohistochemical studies, strongly suggest that the expression of the neonatal forms of MAPs is closely linked to neuronal differentiation and plasticity even in the adult nervous system.

\section{Materials and Methods}

Monoclonal antibodies. The monoclonal MAP5 (AA6) and MAP2 (clone C) antibodies were raised in our laboratory from mice immunized with the MAP fraction of thrice-cycled adult rat brain microtubules. Their production and characterization have been described in detail elsewhere (Huber and Matus, 1984; Riederer et al., 1986). The monoclonal $\beta$-tubulin (clone Tu27), MAP2 (AP14), and tau (tau-1) antibodies were a gift from L. I. Binder (Birmingham, Alabama) (Caceres et al., 1984; Binder et al., 1985). "C" recognizes the high (MAP2a and MAP2b)and low (MAP2c)-molecular weight forms of MAP2, whereas AP14 recognizes only the high-molecular weight form. The two antibodies have previously been used to localize MAP2c immunohistochemically (Tucker et al., 1988a, b).

Brain fractionation. Adult and postnatal day 6 (P6) Sprague-Dawley rats were obtained from Ciba-Geigy Ltd., Basel. Freshly dissected cerebral cortices and olfactory bulbs were homogenized in ice-cold assembly buffer (Karr et al., 1979) without (GTP, containing 0.5 м sucrose, 1 mM phenylmethyl sulfonylfluoride (PMSF; Serva), pepstatin, and antipain (Sigma; $0.01 \mathrm{mg} \cdot \mathrm{ml}^{-1}$ ), as well as the protein phosphatase inhibitors sodium fluoride (Merck; $20 \mathrm{~mm}$ ) and tetrasodium pyrophosphate (Merck; $10 \mathrm{~mm}$ ). Supernatants were fractionated by centrifuging homogenates at $100,000 \mathrm{~g}$ and $4^{\circ} \mathrm{C}$ for $60 \mathrm{~min}$. The supernatants were either used immediately for gel electrophoresis and immunodotting and immunoblotting or stored at $-70^{\circ} \mathrm{C}$ until use.

Gel electrophoresis, immunoblotting, and immunodot assay. For SDSPAGE (Laemmli, 1970), $1.5 \mathrm{~mm}$ slab gels and either a 4-6\%, 4-8\%, or 4-15\% linear gradient of polyacrylamide were used. Following electrophoresis, proteins were electrophoretically transferred to nitrocellulose filter (Towbin et al., 1979). For the immunodot assay, supernatant proteins were dotted using a Bio-Dot SF apparatus (BioRad) and immunostained using previously described methods (Hawkes et al., 1982). Hybridoma supernatants diluted 1:10 (vol/vol) in PBS ( $\mathrm{pH} \mathrm{7.6)} \mathrm{con-}$ taining $1 \%$ nonfat skim milk powder were incubated with the immunoblots and immunodots and stained with HRP-coupled rabbit antimouse secondary antibody (Dakopatts).

Densitometric analyses. Changes in the relative amount of MAP5 on immunodots and relative abundance of MAP5, MAP2, and tau polypeptides on SDS-PAGE immunoblots during development were determined by scanning with a reflectance densitometer (Shimadzu) at a wavelength of $540 \mathrm{~nm}$ as previously described (Riederer and Matus, 1985). Briefly, the linear relationship between the densitometric peak height of immunoperoxidase-stained samples and amount of antigenic protein was established by scanning dilution series of different supernatants. For the immunodot assay, equal amounts of supernatant protein $(1$ and $2 \mu \mathrm{g}$ ) from the different $\mathrm{P} 6$ and adult rat brain regions were used. For immunoblotting experiments, equal amounts of supernatant protein $(10 \mu \mathrm{g})$ corresponding to the different juvenile and adult regions were loaded onto $3-\mathrm{mm}$ wells before SDS-PAGE and immunoblotting. Three sets of P6 and adult rat brain regions were scanned in triplicate. The results of the immunodot assay for MAP5 are expressed as mean pcak hcight \pm SD and as amount of protein relative to the corresponding P6 values. Statistical analyses were carried out using the unpaired Student's $t$ test. Protein concentrations were determined using BioRad reagents and BSA as a standard.

Phosphatase treatment of supernatant fractions. Aliquots (50-60 $\mu \mathrm{l})$ of juvenile or adult rat brain region supernatants (100-125 $\mu$ g protein) were mixed with $450 \mu \mathrm{l}$ of TBS/EDTA buffer $(50 \mathrm{~mm}$ Tris, $135 \mathrm{~mm}$ $\mathrm{NaCl}, 0.1 \mathrm{~mm}$ EDTA, $\mathrm{pH} 8.2$ ) and 50 units of calf intestinal alkaline phosphatase (Boehringer-Mannheim) in the presence of $1 \mathrm{~mm}$ PMSF and incubated at $37^{\circ} \mathrm{C}$ for $12-18 \mathrm{hr}$. Brain fractions incubated under the same conditions except in the presence of $10 \mathrm{~mm}$ 4-nitrophenylphosphate (Boehringer-Mannheim) or in the absence of alkaline phosphatase served as controls.

Northern blot analyses. Poly(A) ${ }^{+}$RNA was isolated from adult rat olfactory bulb using the guanidine isothiocyanate method and oligo(dT) cellulose chromatography (Davis et al., 1986). Poly(A)+RNA was separated on a $0.8 \%$ agarose-formaldehyde gel and transferred to nitrocellulose filter in $10 \mathrm{XSSC}$ and dried at $80^{\circ} \mathrm{C}$ in a vacuum oven (Davis et al., 1986). The MAP2 cDNA probe 38a has been characterized elsewhere (Garner and Matus, 1988). This probe hybridizes with the $9 \mathrm{~kb}$ mRNA that encodes high-molecular weight MAP2 as well as the $6 \mathrm{~kb}$ mRNA that encodes MAP2c. Probe 38a was labeled with ${ }^{32} \mathbf{P}$ by random priming (Feinherg and Vogelstein, 1984). The radioactive cDNA was hybridized with the blot using the buffers and conditions described in Davis et al. (1986). The blot was washed in $0.1 \%$ SSC, $0.1 \%$ SDS at $52.5^{\circ} \mathrm{C}$ for $1.5 \mathrm{hr}$ before exposure with Kodak XAR-5 film.

Immunohistochemistry. Adult rats were anesthetized with sodium pentobarbital (Serva) and perfused through the left ventricle with $4 \%$ paraformaldeliyde in PBS. Whole brains with portions of the olfactory epithelium were removed, postfixed overnight in the same fixative at $4^{\circ} \mathrm{C}$, rinsed in PBS, then cryoprotected overnight in $25 \%$ sucrose in PBS and embedded in O.T.C. (Miles). Coronal and sagittal serial frozen sections through the epithelium and bulb were cut at $14 \mu \mathrm{m}$ and airdried for $2-4 \mathrm{hr}$. The serial sections were stained with monoclonal MAP5, MAP2, tau, and $\beta$-tubulin antibodies as previously described (Tucker et al., 1988a). Since the epitope recognized by the tau antibody is also a phosphorylation site (Papasozomenos and Binder, 1987), alternate adjacent sections for tau staining were treated with calf intestinal alkaline phosphatase to expose masked epitopes as described previously (Tucker et al., 1988a). All sections were counterstained with the Hoechst nuclear dye bisbenzimide (H33258; Boehringer-Mannheim) before being mounted in $50 \%$ glycerol $/ 1 \%$ azide in PBS.

Some sections of the olfactory epithelium were embedded in polyester wax. Adult rats were perfused with $4 \%$ parformaldehyde in PBS, and the olfactory epithelia were postfixed in the same fixative as outlined above. The tissue was then dehydrated in increasing concentrations of ethanol and infiltrated overnight in a 1:1 ( $\mathrm{vol} / \mathrm{vol})$ mixture of ethanol and polyester wax (BDH, Poole, England), and then once again overnight in pure polyester wax at $37^{\circ} \mathrm{C}$. The epithelia were oriented to provide sagittal sections and embedded in wax at room temperature. Sevenmicrometer sections were cut at $4^{\circ} \mathrm{C}$ in a cryostat and collected on cooled water on gelatin-chrome alum-subbed slides. The sections were allowed to dry for $3 \mathrm{hr}$ and were rehydrated through an ethanol series to PBS. The sections were stained with monoclonal antibodies as described above for frozen sections.

\section{Results}

Pattern of MAP expression in developing and adult olfactory bulb and cerebral cortex

The level at which each of the MAPs was expressed in 2 developing and adult brain regions was followed by using specific monoclonal antibodies to stain western blots of brain supernatant proteins. None of these protcins wcrc present at detectable levels in the cold-insoluble pellet from brain homogenates (Riederer and Matus, 1985; Riederer et al., 1986).

MAP5 expression. Figure 1 shows that MAP5 in developing brain can be resolved into two components, a sharp upper band (MAP5a) and a broad lower band (MAP5b). MAP5a and MAP5b were present in approximately equal amounts in the supernatant fractions from the developing olfactory bulb and cerebral cortex (Fig. 1; lanes marked P6). In accordance with previous reports that MAP5 is more abundant in developing rat brain than in adult brain (Riederer et al., 1986), MAP5 levels were higher in developing than adult cortex (Fig. 1, CRT, compare lanes P6 and $A$ ). In addition, we found that MAP5a was absent from the adult cerebral cortex (Fig. 1, CRT, lane A). In contrast, there was no significant drop in the overall level of MAP5 during maturation of the olfactory bulb, and the relative abundance of 


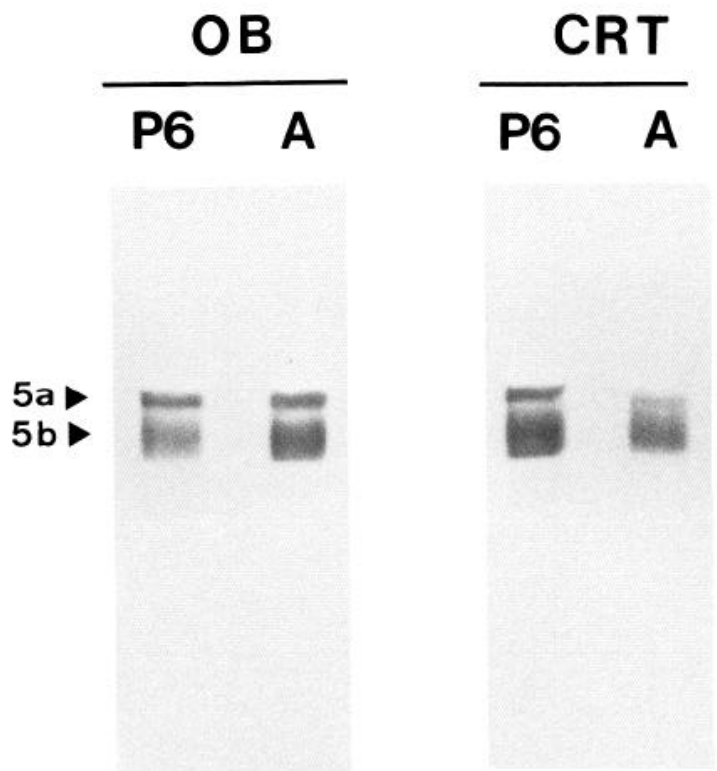

Figure 1. Developmental expression of MAP5 in the rat olfactory bulb $(O B)$ and cerebral cortex $(C R T)$. The SDS-PAGE (4-8\% acrylamide) immunoblot of $\mathrm{P} 6$ and adult $(A)$ regions was stained with monoclonal MAP5 antibody. The immunoblot is shown from the region corresponding to the start of the running gel to the position of the 116,000 Da marker. In the P6 brain regions, MAP5 resolves into two bands, a narrow band of approximately $320,000 \mathrm{Da}$ (MAP5a) and a broader band just below $(M A P 5 b)$. In the adult cerebral cortex, MAP5 levels decrease significantly, with MAP5b being the prominent form expressed. There is no apparent change in the MAP5 expression pattern in the olfactory bulb.

MAP5a and MAP5b in the adult olfactory bulb was indistinguishable from that in the corresponding developing tissue (Fig. 1, OB).

Table 1 shows the MAP5 levels quantitated by densitometric measurements. In the developing cerebral cortex and olfactory bulb, the levels of MAP5 relative to total brain supernatant protein were comparable. In the adult cerebral cortex, the abundance of MAP5 was approximately 3-fold lower than in developing tissue. In contrast, MAP5 expression in the adult olfactory bulb remained as high as in the developing olfactory bulb.

MAP5 phosphorylation during development. Figure 2 shows that MAP5a represents a highly phosphorylated form of MAP5. When supernatant proteins from developing cortex were treated with alkaline phosphatase, MAP5a disappeared, and only a single band that comigrated with MAP5b in the untreated sample was detected (Fig. 2, CRT, lanes marked P6- and P6+). Under the conditions used for dephosphorylation, none of the characteristic proteolytic fragments of MAP5 (see Riederer et al., 1986) were generated, eliminating the possibility of proteolysis as a contributory factor in the disappearance of MAP5a. Also, when the phosphatase inhibitor 4-nitrophenylphosphate was added to the reaction mixture, no decrease in MAP5a levels occurred (not shown), indicating that dephosphorylation was responsible for the shift in molecular weight. No change in MAP5b was induced by dephosphorylation, and the amount of anti-MAP5 reactive material migrating as MAP5b increased after alkaline phosphatase treatment, presumably because of dephosphorylated MAP5a comigrating with MAP5b.

Adult tissue shows marked differences in MAP5 phosphorylation between olfactory bulb and cortex (Fig. 2). Results with

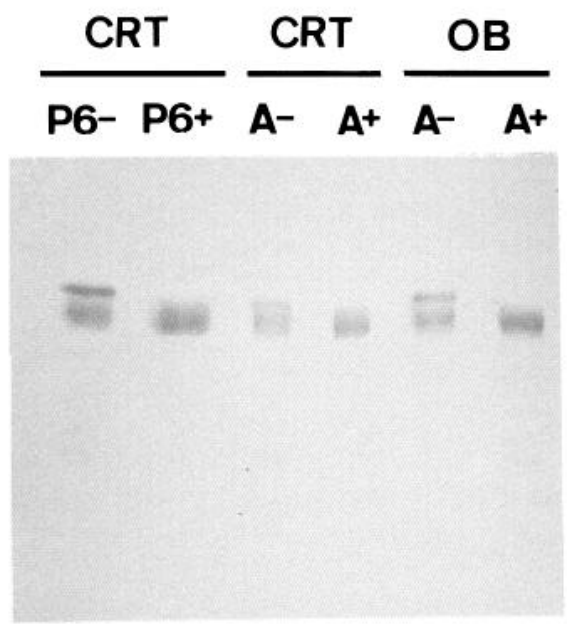

Figure 2. Effect of phosphatase treatment on electrophoretic mobility of MAP5. The SDS-PAGE (4-8\% acrylamide) immunoblot was stained with monoclonal MAP5 antibody and is shown from the region corresponding to the start of the running gel to the migration point of the 116,000 Da marker. Following treatment of the P6 cerebral cortex with alkaline phosphatase $(C R T$, lane $P 6+)$, a single band comigrating with MAP5b in the control well $(P 6-)$ is stained. The electrophoretic pattern of MAP5 in the adult cerebral cortex (specifically represented by MAP5b) is somewhat narrower following alkaline phosphatase treatment (CRT, $A-$ and $A+$ ). The anti-MAP5 staining pattern of the adult olfactory bulb is represented by both MAP5a and MAP5b. Following alkaline phosphatase treatment, a single band comigrating with MAP5b is found $(O B, A-$ and $A+)$.

adult olfactory bulb (Fig. 2, OB) resembled those from the developing cortex. Before dephosphorylation, MAP5a could be resolved. Following treatment with alkaline phosphatase, MAP5a disappeared, and a concomitant increase in MAP5b was apparent. However, MAP5 from adult cerebral cortex contains no MAP5a, and the only effect of alkaline phosphatase treatment was a slight decrease in the width of the MAP5b band (Fig. 2, $\mathrm{CRT}$, lanes marked $\mathrm{A}-$ and $\mathrm{A}+$ ). These results indicate that although the MAP5 in the cortex becomes dephosphorylated on maturation, the olfactory bulb retains the embryonic pattern of MAP5 phosphorylation in the adult.

$M A P 2$ expression. MAP2 in neonatal rat brain has been shown to consist of two components, MAP2b (280,000 Da) and MAP2c $(70,000 \mathrm{Da})$ (Riederer and Matus, 1985). Figure $3 A$ shows that this pattern of MAP2 expression could be found for the P6

Table 1. Expression of MAP5 in the developing rat brain regions

\begin{tabular}{lll} 
& Peak height $(\mathrm{cm})$ & $\begin{array}{l}\text { Relative } \\
\text { protein }\end{array}$ \\
\hline $\begin{array}{l}\text { Olfactory bulb } \\
\text { P6 }\end{array}$ & $7.1 \pm 0.6$ & 1.0 \\
Adult & $7.1 \pm 1.6$ & 1.0 \\
Cerebral cortex & & \\
P6 & $8.1 \pm 1.4$ & 1.0 \\
Adult & $3.3 \pm 0.8^{a}$ & 0.4
\end{tabular}

Immunodots stained with anti-MAP5 and HRP-coupled secondary antibody were scanned by reflectance densitometry. Values represent the means \pm SD of reflectance peak heights $(\mathrm{cm})$ from 3 sets of $\mathrm{P} 6$ and adult rat brain regions done in triplicate and the corresponding amount of protein relative to the corresponding P6 level. ${ }^{a} p \leq 0.01$ (Student's $t$-test) vs corresponding P6 value. 


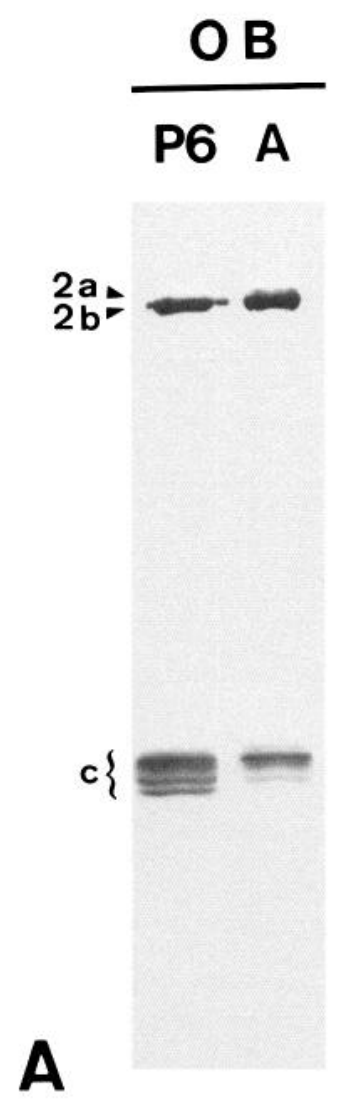

\section{CRT

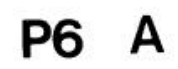

A

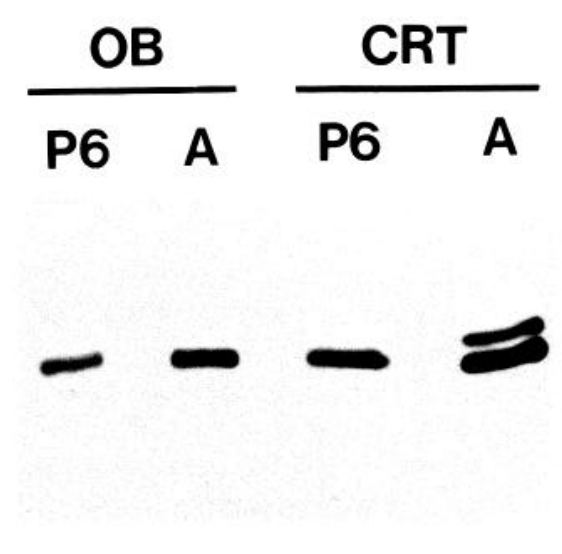

Figure 3. SDS-PAGE (A, 4-15\% acrylamide; $B, 4-6 \%$ acrylamide) immunoblot stained with monoclonal MAP2 antibody (clone $C$ ) showing developmental expression of MAP2 in the P6 (P6) and adult $(A)$ rat olfactory bulb $(O B)$ and cerebral cortex $(C R T)$. In each of the $\mathrm{P} 6$ regions, MAP2 $b$ and MAP2c are the prominent polypeptides. MAP2 $c$ resolves into three distinct proteins. In the adult cerebral cortex, MAP2c expression is significantly decreased $(A, C R T$, lane $A)$, whereas MAP2a levels equal those of MAP2b $(B, C R T$, lane $A)$. In the adult olfactory bulb, however, many of the MAP2c polypeptides are abundant $(A, O B$, lane $A)$, whereas MAP2a staining is barely detectable $(B, O B$, lane $A)$. Standards corresponding (from the top of the nitrocellulose) to 200,000, $116,000,92,000,66,000$, and $45,000 \mathrm{Da}$ are shown on the right of $A$.

olfactory bulb (OB, lane P6) and cerebral cortex (CRT, lane P6). In both brain regions, MAP2c resolved into 3 bands, of which the slowest migrating was the most prominent. The relative amounts of MAP2b and MAP2c, as determined by densito-

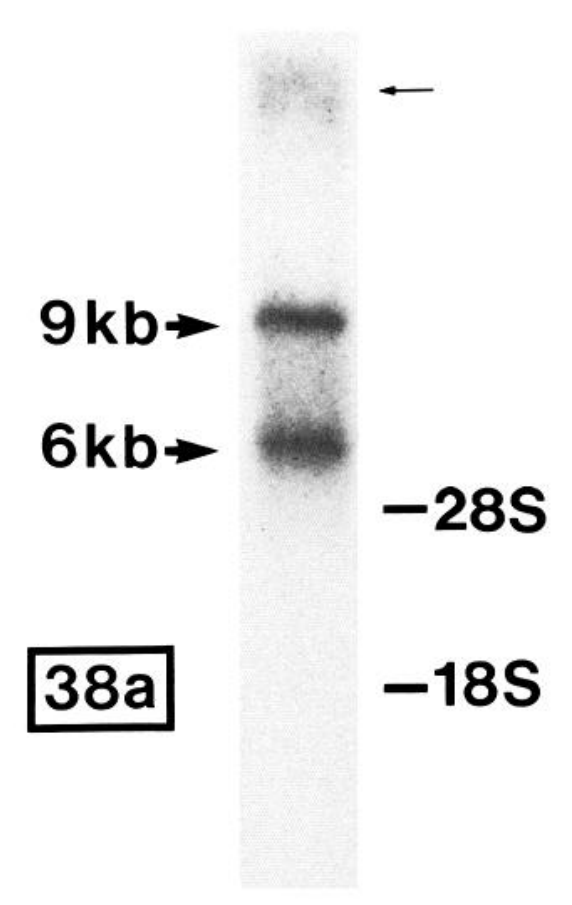

Figure 4. Northern blot analysis of adult olfactory bulb transcripts using a MAP 2 cDNA. Poly (A) ${ }^{+}$RNA was separated on a $0.8 \%$ agaroseformaldehyde gel before transfer to nitrocellulose and hybridization to the ${ }^{32} \mathrm{P}$-labeled MAP2 cDNA probe $38 \mathrm{a}$. In the adult olfactory bulb, both the early $6 \mathrm{~kb}$ mRNA and the $9 \mathrm{~kb}$ mRNA of high-molecular weight MAP2 are present. The arrow indicates the origin of the gel. The positions of the $28 \mathrm{~S}$ and $18 \mathrm{~S}$ ribosomal bands, determined by running nonpoly $(\mathrm{A})^{+} \mathrm{RNA}$ in a lane adjacent to the poly $(\mathrm{A})^{+} \mathrm{RNA}$, are indicated on the right.

metric scanning of immunoblots, were approximately equal for the 2 neonatal regions probed (not shown).

The pattern of MAP2 expression in adult cerebral cortex was different from the corresponding developing tissue and conformed to that previously reported in the whole rat brain (Riederer and Matus, 1985). MAP2c was barely detectable, whereas MAP2a was present and equally abundant with MAP2b (Fig. 3, $A, B$, CRT, lane A). The adult olfactory bulb, in contrast, retained a pattern of MAP2 expression similar to that of developing brain (Fig. 3, $A, B$, OB, lane A). The level of MAP2b was increased slightly over that in the developing olfactory bulb, but there was almost no detectable MAP2a. MAP2c continued to be expressed, although the relative abundance was lower than that in the developing olfactory bulb. The two minor bands of MAP2c were barely detectable. This is most probably because they are present in much smaller amounts than the main MAP2c component, even in developing tissue. Northern blot analysis of the adult olfactory bulb showed that this region was highly enriched in the $6 \mathrm{~kb}$ mRNA encoding MAP2c as well as in the $9 \mathrm{~kb}$ mRNA (Fig. 4). When whole adult brain poly(A)+RNA is probed with $38 \mathrm{a}$, only the $9 \mathrm{~kb}$ mRNA is detected (Garner and Matus, 1988).

Tau expression. The pattern in tau expression in the olfactory bulb resembled that of MAP2 in that the form of tau expressed in the developing tissue was retained in the adult. In both the developing cerebral cortex and olfactory bulb, there was a single tau component corresponding to the "juvenile" tau ( $T_{j}$, Fig. 5 , lanes P6) initially described by Nunez and colleagues (Francon 
et al., 1982). In the adult cortex, the tau forms characteristic of adult tissue (Francon et al., 1982) are expressed (Fig. 5, CRT, lane A). In the adult olfactory bulb, these characteristic adult tau forms were either absent or present at very low levels compared to adult cortex (Fig. 5, OB, lane A).

\section{Distribution of MAP5, MAP2, and tau in the olfactory system}

We examined the distribution of these MAPs in the olfactory system to determine if their expression could be correlated with those neuronal elements that are highly plastic or undergoing constant regrowth in this adult region. The neurogenic and plastic components include the olfactory receptor neurons in the sensory epithelium, which are constantly renewed in the adult, the olfactory nerve, which contains the axons of the receptor neurons, and the olfactory bulb, which contains the mitral cell dendrites that are being re-innervated. These different elements are illustrated in Figures $6 A$ and $8 A$.

The sensory epithelium. Figure $6 \mathrm{~B}$ shows the pattern of tubulin distribution using an antibody against $\beta$-tubulin. As expected, staining was present in all cellular elements, including the luminal cilia of the receptor cells, and was particularly intense in olfactory axon bundles in the submucosa. Anti-MAP5 staining (Figs. $6 C ; 7 A, B$ ) was intense in the sensory projections of the receptor cells but was not present in the cilia (cf. Fig. 6, $B, C$ ). Anti-MAP5 staining was present but relatively weak in receptor neuron cell bodies. Anti-MAP5 stained only the receptor cells and not the supporting cells (Fig. 7, B, C). The expression of the high molecular weight form of MAP2 in the sensory epithelium was very low and was restricted to a few scattered neuronal cell bodies and their sensory projections (Fig. 6D). By contrast, anti-tau staining was intense in both the cell bodies and sensory projections of the olfactory receptor neurons and in the axon bundles of the vomeronasal nerve (Fig. $6 E$ ). Weaker anti-tau staining of some nerve fascicles in the lamina propria and in the area around the vomeronasal nerve also could be detected. Because of nonspecific staining of blood vessels by the secondary antibody, the presence of tau in these regions could not be determined. The staining patterns observed with each of the antibodies appeared to be homogeneous throughout the olfactory epithelium; i.e., no gradient or patches of staining were observed.

Olfactory axons and the olfactory bulb. Figure $8 A$ shows the elements of the region that are represented in the immunohistochemical micrographs. The olfactory axons were intensely stained by anti-MAP5. In the olfactory bulb, there was strong anti-MAP5 staining in the cell bodies and dendrites of mitral cells and in periglomerular neurons (Fig. $8 B$ ). However, the highest levels of MAP5 were present in the axons of the olfactory nerve (Fig. $8 B$ ).

Staining with monoclonal antibodies against the high-molecular weight form of MAP2 confirmed its well-established selective association with dendrites (see Matus, 1988, for review). In the olfactory bulb, anti-MAP2 staining was most intense in the cell bodies and dendrites of mitral cells and periglomerular neurons (Fig. 8C). Previous studies in our laboratory have shown that the spatial distribution of high- and low-molecular weight forms of MAP2 in the developing CNS can be discriminated using a combination of monoclonal antibodies (Tucker et al., 1988a). The same method was applied to the adult olfactory system. Alternate sections were stained with either the $\mathrm{C}$ monoclonal antibody, which recognizes both high- and lowmolecular weight MAP2, or AP14, which recognizes only the

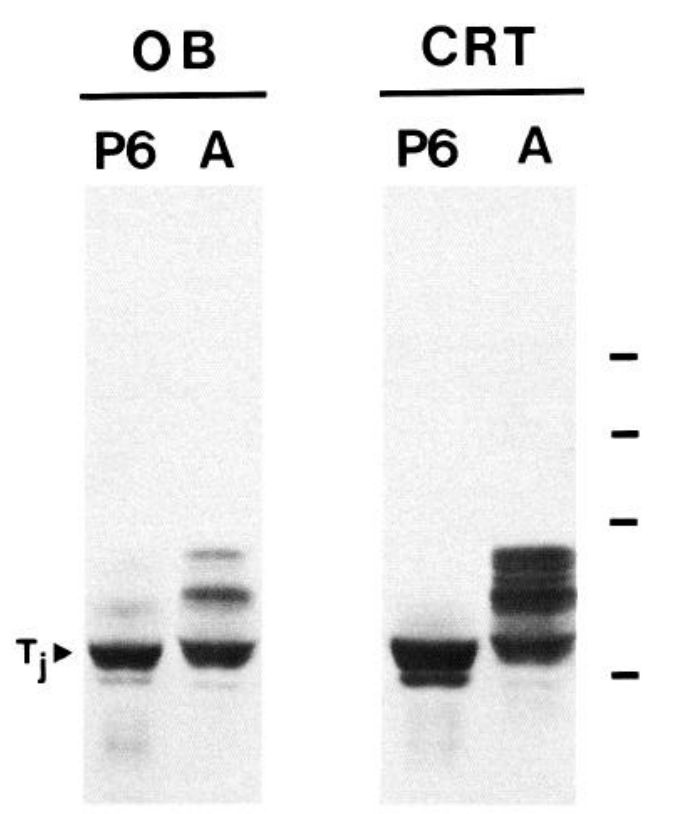

Figure 5. SDS-PAGE (4-15\% acrylamide) immunoblot staining with monoclonal tau antibody showing developmental expression of tau in the P6 and adult $(A)$ rat olfactory bulb $(O B)$ and cerebral cortex $(C R T)$. In the P6 regions, a prominent protein of $48,000 \mathrm{Da}$ is expressed. The adult cortex expresses tau polypeptides between 52,000 and $68,000 \mathrm{D}$. In the adult olfactory bulb, however, these higher molecular weight bands are expressed in significantly decreased amount. Only the relevant portion of the immunoblot is shown. Molecular weight markers corresponding to $116,000,92,000,66,000$ and $45,000 \mathrm{Da}$ are shown on the right.

high-molecular weight form. The distribution of the early, lowmolecular weight form can then be inferred from the difference between the two staining patterns (Tucker et al., 1988a). However, in the adult olfactory bulb (Fig. $9 A, B$ ) and sensory epithelium (not shown), no differences in the 2 staining patterns could be seen.

Antibodies against tau stained the olfactory nerve in a highly selective manner, mainly marking only a small subset of the axonal bundles. These bundles were grouped medially and dorsally in coronal sections and coincide with the localization of the vomeronasal nerve. Weaker anti-tau staining was observed in the deeper parts of the olfactory nerve layer. Thus, the distribution of tau in the olfactory nerve was very different from that of both MAP5, which had a uniform distribution (Fig. 8B), and MAP2, which was completely absent from the nerve (Fig. $8 C$ ). In the olfactory bulb, antibody against tau stained cell bodies and processes in the granule cell layer and external plexiform layer, as well as mitral cells and periglomerular neurons (Fig. 8D).

Since previous studies have shown that the epitope recognized by the anti-tau antibody may be masked by phosphorylation (Papasozomenos and Binder, 1987), we investigated the possibility that the restricted tau distribution in the olfactory nerve was the result of epitope masking. We have previously demonstrated the efficacy of this method in unmasking these epitopes (Tucker et al., 1988a). Alkaline phosphatase treatment of sections, however, did not alter the anti-tau staining pattern (Fig. 9C, D), demonstrating that the restricted staining pattern was not the result of epitope masking by phosphorylation. 


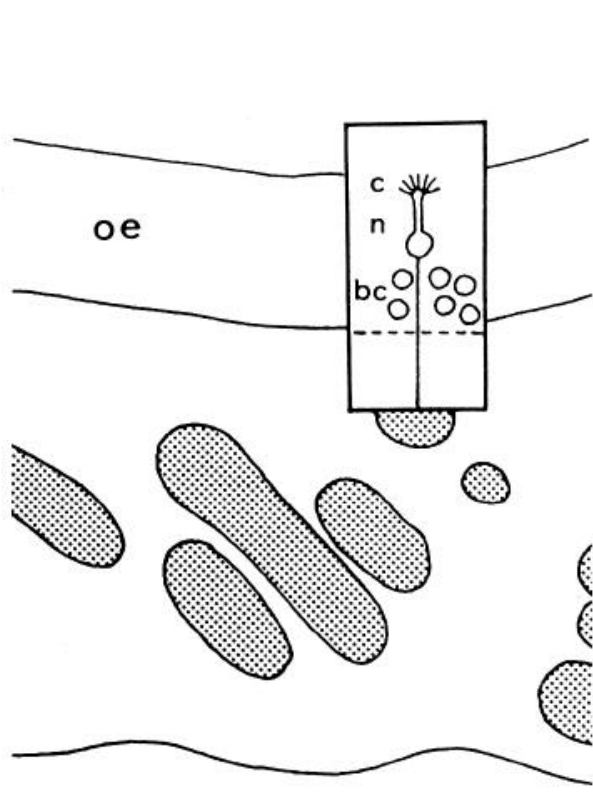

6A

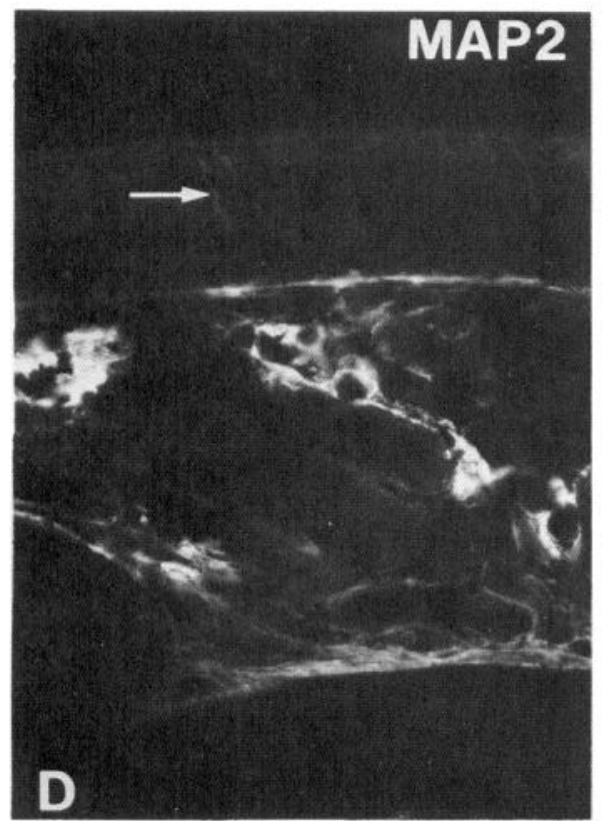

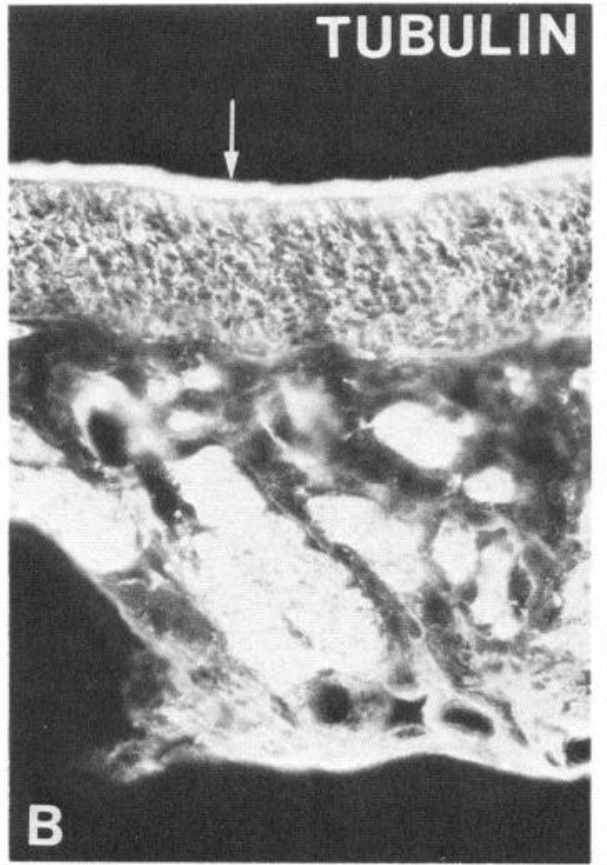
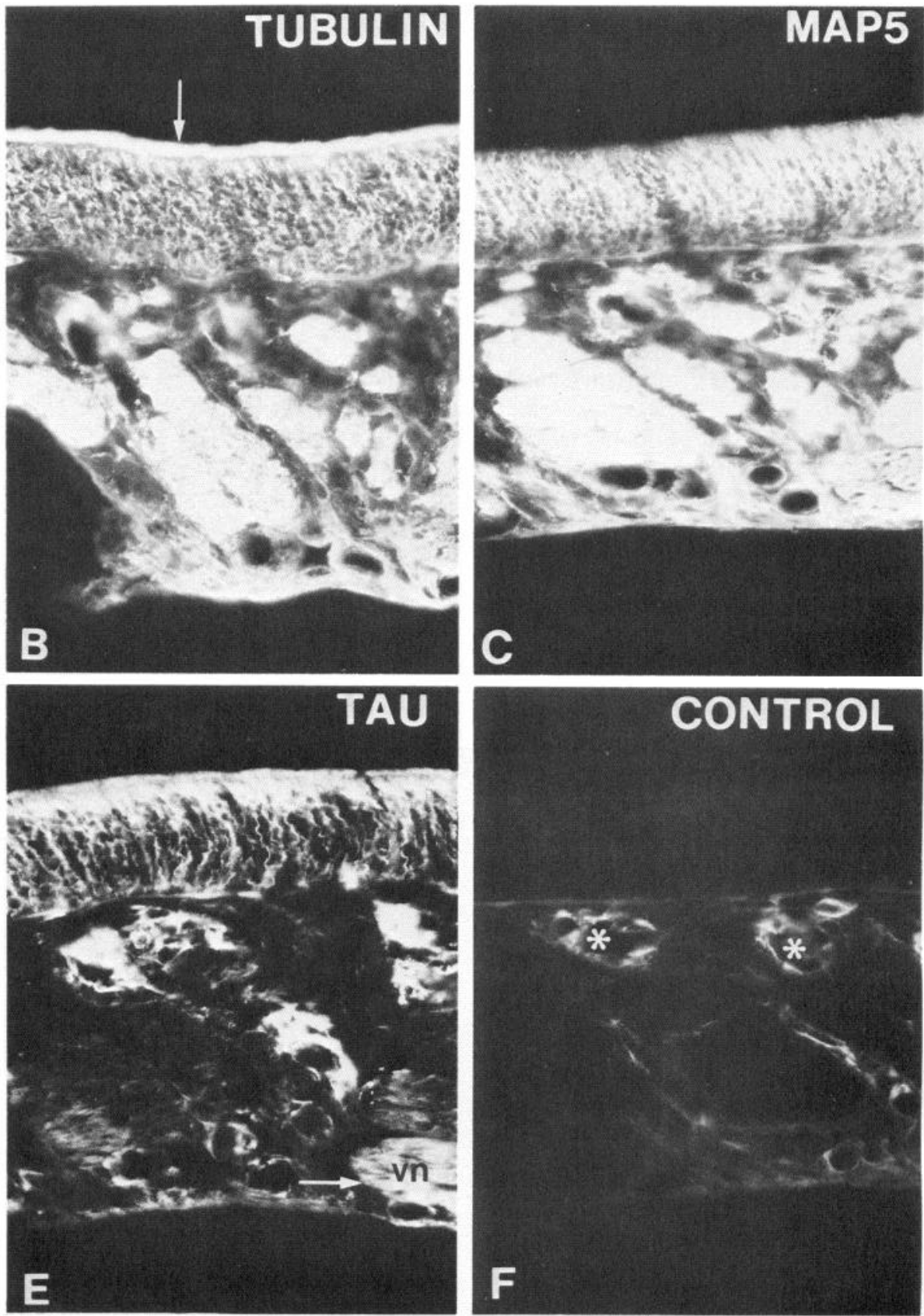

Figure 6. Immunohistochemical localization of $\beta$-tubulin, MAP5, MAP2 (clone C), and tau in the adult rat olfactory epithelium and submucosa. Serial frozen sections were used. $A$, Layers of the epithelium can be seen in the schematic representation. $c$, cilia; $s c$, supporting cells; $n$, neuronal layer; $b c$, basal cells. The inset shows the arrangement of a sensory neuron. $B$, The anti- $\beta$-tubulin stains the cilia (arrow) lining the epithelium as well as sensory cells and their projections. $C$, Anti-MAP5 stains cell bodies and processes within the olfactory epithelium as well as axon bundles in the submucosa. The basal cells appear to be unstained. $D$. Anti-MAP2 staining is very weak and restricted to a small subset of cell bodies and dendrites (arrow). E, Anti-tau stains neuronal cell bodies and their sensory processes. In the submucosa, anti-tau staining is most intense in the axonal bundles of the vomeronasal nerve ( $v n$; arrow). $F$, The control section shows faint staining of connective tissue and blood vessels (asterices) by the secondary antibody.

\section{Discussion}

The major finding of the present study is that the adult rat olfactory system expresses forms of MAP5, MAP2, and tau that are characteristic of the developing brain. It is known that the adult olfactory system has unique growth properties: it is the only region in the adult where neurogenesis occurs (Graziadei and Monti-Graziadei, 1979). One consequence of the neuro- genesis of receptor neurons is that the olfactory bulb is continually being reinnervated. The mitral cell dendrites in the olfactory bulb that synapse with the axons of these receptors must, therefore, remain in a state of high plasticity. Our results suggest that the expression of the early forms of MAPs by the olfactory system may be a necessary prerequisite for neurite outgrowth and plasticity, even in the adult.

A number of earlier studies have proposed a possible rela- 


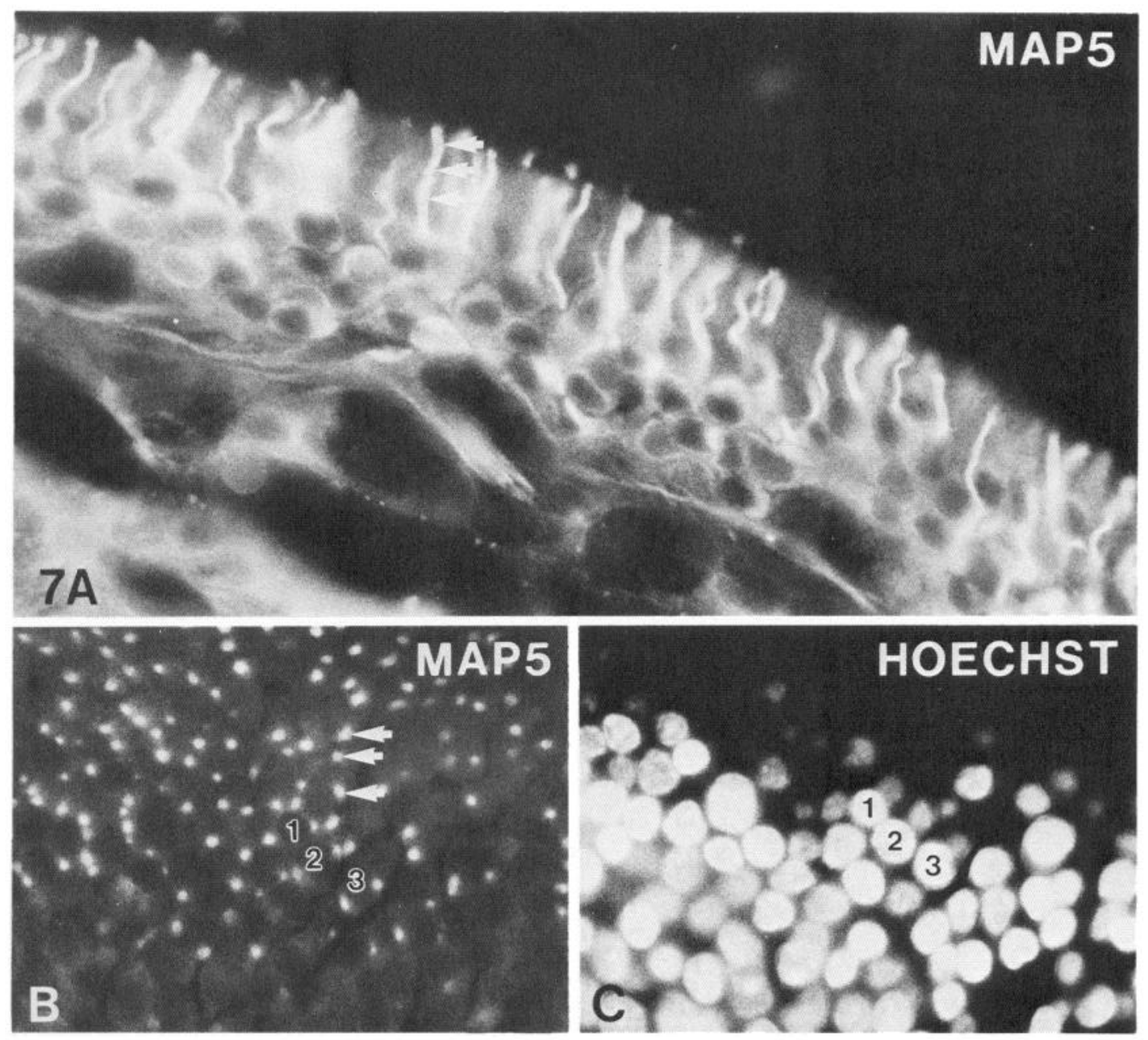

Figure 7. High magnification of anti-MAP5 staining in the adult rat olfactory epithelium on polyester wax sections. A, Anti-MAP5 staining is intense in the sensory projections of the olfactory receptor neurons (arrows) and can also be detected in the cell bodies of the receptor neurons. $B$, Staining of a glancing section through the outer portion of the olfactory epithelium reveals intense staining within the sensory projections (arrows) but no staining in the surrounding supporting cells. The cell bodies of three supporting cells are numbered $1-3$. $C$, The same section shown in $B$ stained with Hoechst nuclear dye. The nuclei of the three supporting cells numbered in $B$ are similarly numbered.

tionship between early MAPs and neuronal growth potential. First, the early MAPs are expressed in differentiating neurons throughout the developing brain and are switched off when the mature neuronal morphology becomes established and maintained (reviewed by Matus, 1988). Second, Busciglio et al. (1987) have shown that during lesion-induced axon sprouting in the hippocampus, there is a reappearance of the juvenile tau that is absent from the normal adult hippocampus. The results of the present study, however, provide the most convincing evidence for this relationship to date, since axonal regrowth and dendritic reinnervation have been well studied and quantitated in the adult mammalian olfactory system (Graziadei and MontiGraziadei, 1979).

We used monoclonal antibodies specific for MAP5, MAP2, and tau for our biochemical and immunohistochemical studies. For MAP5, we show that this cytoskeletal component is expressed by both the neurogenic and plastic regions of the olfactory system. The sensory projections of the epithelial receptor neurons and their axons were found to be particularly rich in MAP5, and some MAP5 was also present in the mitral cell dendrites in the olfactory bulb. These differences in MAP5 con- tent suggest that this cytoskeletal protein may be involved in regulating neurite outgrowth. Its presence in the mitral cell tufts localized in the glomeruli suggests that it may also be playing some role in the control of plasticity, perhaps in concert with other early cytoskeletal proteins. This neuron-specific protein has previously been shown to be the first MAP expressed by differentiating neurons in vivo (Tucker and Matus, 1987; Tucker et al., 1988a), and its levels increase significantly when neurite outgrowth is induced in PC12 cells after treatment with NGF (Brugg and Matus, 1988; Drubin et al., 1988). The present results reinforce these earlier studies and, additionally, show that the expression of high levels of MAP5 is directly related to the growth state of the neuron.

Our biochemical and immunohistochemical studies with MAP2 and tau suggest that the early forms of these proteins may be closely involved in the control of neuronal plasticity. This was reflected by our observation that MAP2 was particularly abundant in the mitral cell dendrites of the olfactory bulb. We also observed that it was virtually absent in the dendritelike projections of the olfactory receptor neurons. These sensory projections, however, were rich in tau. It is possible that the 

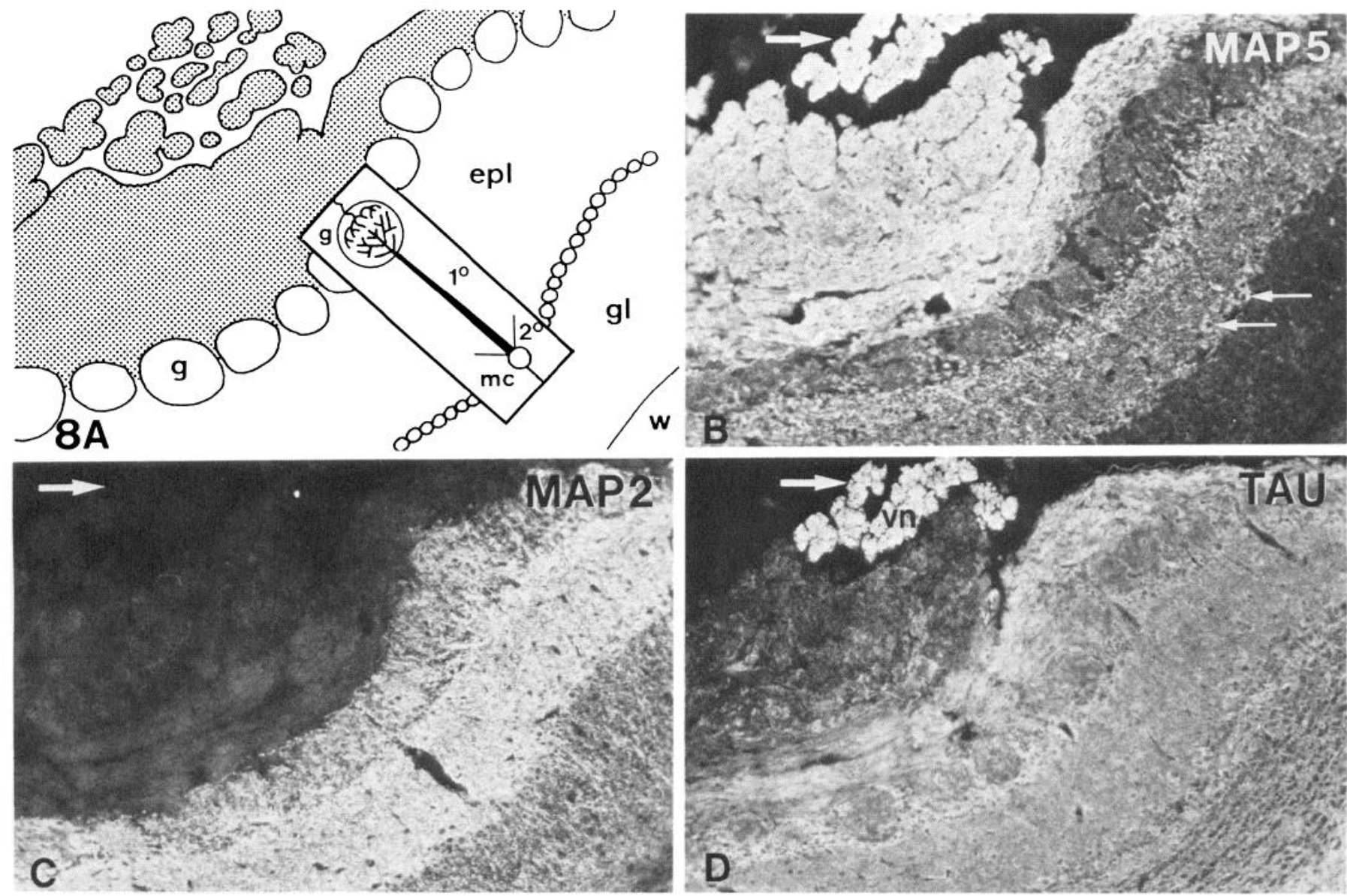

Figure 8. Immunohistochemical localization of MAP5, MAP2 (clone C), and tau in the adult rat olfactory bulb. Serial frozen sections were used. $A$, The different layers of the olfactory bulb can be seen in the schematic representation. $g l$, granular layer; $m c$, mitral cell body layer; $e p l$, external plexiform layer; $g$, glomerular layer; on, axons of the olfactory nerve. The boxed inset shows the primary $(19)$ and secondary $(29)$ dendritic branches of a mitral cell in the glomeruli and external plexiform layer, respectively. $B$, Anti-MAP5 is found within the cell bodies and processes associated with neurite outgrowth and synaptogenesis. Anti-MAP5 staining is found in mitral cell bodies (arrows) and their dendrites within the glomeruli and external plexiform layer. Anti-MAP5 also stains axons within the olfactory nerve intensely. $C$, Anti-MAP2 staining is found in the dendritic elements involved in the turnover of receptor axons. Staining is found in the external plexiform layer and glomeruli as well as in periglomerular neurons. Less intense staining is found in the granular layer. $D$. Anti-tau stains cell bodies and processes in the granular layer and external plexiform as well as periglomerular and mitral cells. Staining is most concentrated in the axonal bundles of the vomeronasal nerve (vn; arrow).

absence of extensive branching and arborization by the dendritelike sensory projections, which are characteristic features of most other dendrites, may explain the disparate abundance of MAP2 and tau. This supports the notion that MAP2 is involved in the establishment of the more typical branching morphology of dendrites (see review by Matus et al., 1990).

We have also observed a restricted distribution for tau within the olfactory nerve. The presence of tau-positive axons at the dorsomedial region of both bulbs suggested that they may be the vomeronasal axons (Wilson and Raisman, 1980). This was confirmed when we compared the location of the tau-positive axonal bundles with the location of the vomeronasal axons on sections of the adult rat olfactory bulb provided by G. Raisman (National Institute of Medical Research, Mill Hill, London). The selectivity was not an artifact of the fixation method, since we observed this pattern on all olfactory bulbs sectioned. Furthermore, a restricted pattern for tau could also be observed in axonal bundles in the submucosa of the olfactory epithelium. Also, this restricted pattern was not observed in the layer of receptors neurons in the epithelium or in the layers of the olfactory bulb or in other regions of the CNS (Tucker et al., 1988a;
Viereck et al., 1988). Masking of the tau-1 epitope in olfactory axons by phosphorylation was also ruled out since we saw an identical staining pattern after sections were treated with alkaline phosphatase before the staining. This method is known to be effective in unmasking phosphorylated tau-1 epitopes in CNS tissue (Tucker et al., 1988a). It is known that the vomeronasal axons have a much lower turnover rate than the main olfactory axons, although they retain a high growth potential after section of the nerve (Barber, 1981a, b). Earlier observations have reported that tau appears late in extending neurites during brain development (Tucker et al., 1988a). The relative paucity of tau in the olfactory nerve and its restriction to the axons of the vomeronasal organ is consistent with previous studies suggesting that tau is not directly involved with the early phases of neurite outgrowth but more likely involved in axon stabilization.

Our biochemical data indicated that the adult olfactory bulb expressed some of mature forms of tau. Immunohistochemically, tau was also present in the more anatomically stabilized regions of the olfactory bulb, such as the axons of the olfactory tract. These or other axons not directly associated with turnover 

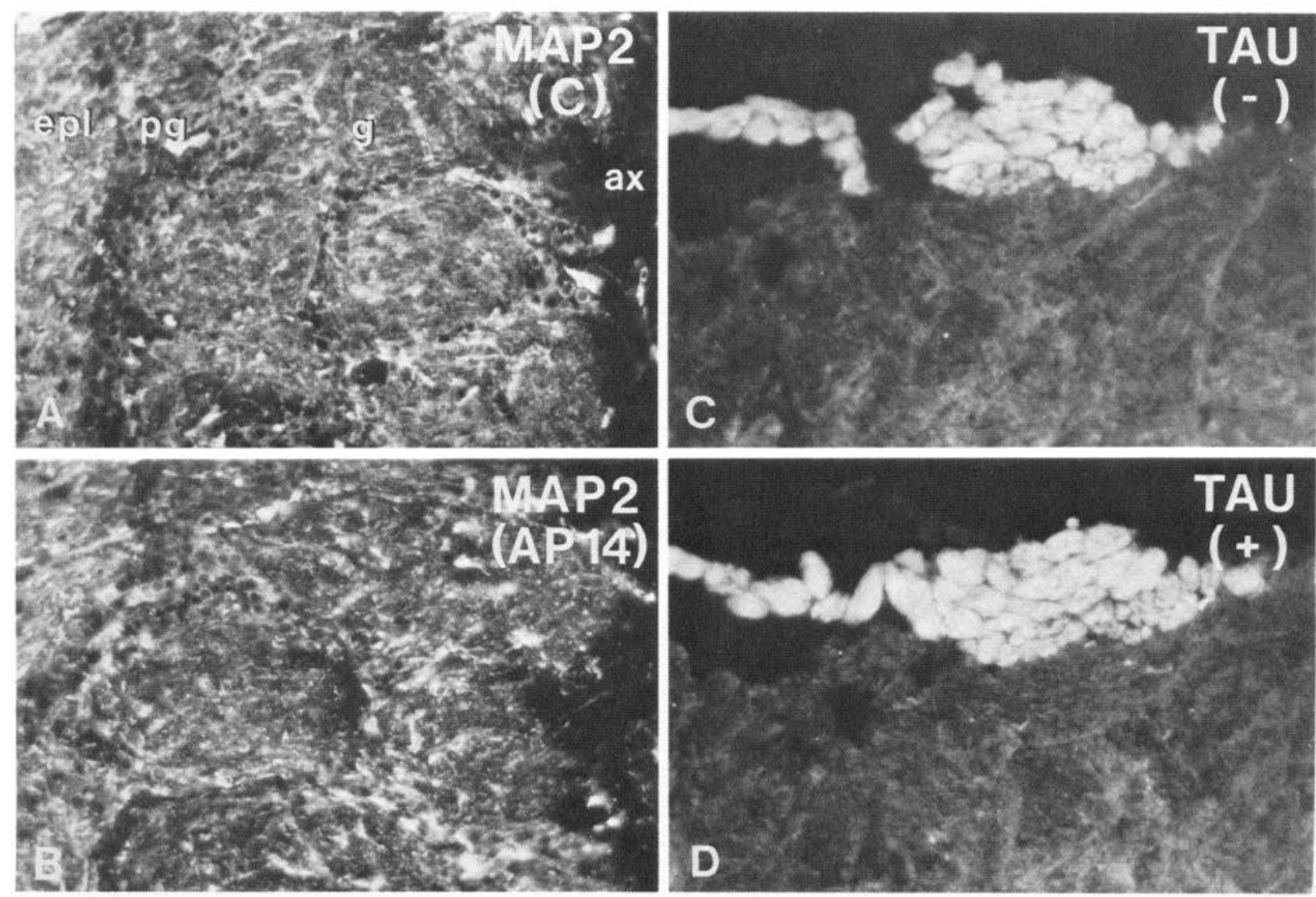

Figure 9. $A$ and $B$, Localization of high- and low-molecular weight forms of MAP2 in the adult olfactory bulb. $A$, Staining pattern obtained with clone C, which stains MAP2b and MAP2c. B, The distribution of MAP2b (antibody AP14) on an adjacent section overlaps that of MAP2c. epl, external plexiform layer; $p g$, periglomeruli; $g$, granular layer; $a x$, axon bundles. $C$ and $D$, effect of alkaline phosphatase treatment on anti-tau staining in the adult olfactory nerve. The anti-tau staining pattern $(C)$ is unchanged following pretreatment of an adjacent section with alkaline phosphatase $(D)$, indicating that the subset of axons stained with anti-tau is not the result of epitope masking by phosphorylation.

may be the source of the mature forms of tau detected on western blots.

What purpose can be served by the expression of a distinct early set of MAPs? This is probably best appreciated by considering the differences between early and late MAP forms as stabilizers of microtubules. It has been shown that MAPs from the developing brain are significantly less effective in stimulating tubulin polymerization in vitro than are adult brain MAPs (Lennon et al, 1980). Faivre et al. (1985) have shown that during development, when growth-associated MAPs are present, the majority of microtubules are cold labile, whereas at a later time, when late MAPs have appeared, the majority of microtubules are cold stable. Since microtubule depolymerization is correlated with lability of neurite morphology (Bray et al., 1978; Matus et al., 1986), the presence of early MAPs may provide anatomical plasticity in a system where morphological renewal is continuous throughout life.

Our observations suggest that there may also be a close relationship between the phosphorylation of MAP5 and the growth potential of neurons. We identified a highly phosphorylated form of MAP5, MAP5a, by treating supernatants with alkaline phosphatase before SDS-PAGE and immunoblotting. The shift in molecular weight that we report in the present study has been reported for a number of other cytoskeletal proteins, including the neurofilament triplet (Julien and Mushynski, 1982), tau (Lindwall and Cole, 1984), and MAP2c (Garner et al., 1988; Tucker et al., 1988c). A previous in vitro study, using PC1 2 cells induced to grow axons by NGF, showed that neurite outgrowth is associated with an increase in MAP5 phosphorylation (Aletta et al., 1988). It is highly probable that phosphorylation is important for the function of MAP5 in differentiating neurons. In vitro studies using MAP2 and tau have shown that their potency as promoters of tubulin polymerization is greatly reduced by phosphorylation (Murthy and Flavin, 1983; Lindwall and Cole, 1984). Phosphorylation also exerts an influence on the interactions between different cytoskeletal components. The interactions between microtubules and actin (Nishida et al., 1981; Seldon and Pollard, 1983) or neurofilaments (Letterier et al., 1982; Heimann et al., 1985) are modulated by phosphorylation in vitro. It is possible that the activity of MAP5 may also be modulated by phosphorylation in an analogous manner. The continued phosphorylation of MAP5 in the adult olfactory system thus suggests that in a system where neurite growth is taking place the posttranslational modification of MAP protein is regulated to favor microtubule lability and hence morphological plasticity.

Our proposal that the early forms of MAPs are related to neurite outgrowth and neuronal plasticity is further supported by studies undertaken in the olfactory system with other markers of neuronal growth. In addition to expressing the neonatal forms of MAPs, the olfactory epithelial neurons in the adult retain other juvenile biological characteristics. For example, the receptors continue to express vimentin rather than neurofilament proteins (Schwob et al., 1986). Cell surface and extracellular 
matrix antigens associated with neurite outgrowth also continue to be expressed in this region of the adult. They include the NII.E (Stallcup et al., 1985) and growth cone-specific (Wallis et al., 1985) glycoproteins, as well as the embryonic form of N-CAM (Miragall et al., 1988) and the secreted protease inhibitor with neurite-promoting activity, glia-derived nexin (Reinhard et al., 1988). Is the expression of these proteins regulated by a common mechanism, and at what level is it operative? For the MAPs, it is possible that the expression of the neonatal forms of MAP5, MAP2, and tau is regulated at various levels. Previous studies in our laboratory (Garner and Matus, 1988) have shown that the switch in expression of MAP2 forms that occurs during brain development may involve the alternate splicing of the primary MAP2 mRNA. The low- and high-molecular weight forms of MAP2 are translated from separate mRNA species that are transcribed from the same gene. During development of the rat brain, transcription of the smaller $6 \mathrm{~kb}$ mRNA is turned off concomitant with the decrease in MAP2c (Garner and Matus, 1988). The fact that we have demonstrated the presence of both MAP2 mRNA species in the adult olfactory bulb is further evidence that it shares characteristics with the developing brain and that it lacks the regulatory cues that cause the transcription of the smaller mRNA to be turned off. Finally, as the present results for MAP5 show, the state of MAP phosphorylation can also be regulated in a manner related to neuronal growth potential. How these diverse regulatory events are coordinated remains to be determined, but the fact that they are so closely linked both during development and in adult tissues where neuronal growth and plasticity take place indicates that the neonatal MAPs are an essential component of the molecular mechanism of neuronal morphogenesis.

\section{References}

Aletta, J. M., S. A. Lewis, N. J. Cowan, and L. A. Greene (1988) Nerve growth factor regulates both the phosphorylation and steady-state levels of microtubule-associated protein 1.2 (MAP1.2). J. Cell Biol. 106: 1573-1581.

Barber, P. C. (1981a) Axonal growth by newly-formed vomeronasal neurosensory cells in the normal adult mouse. Brain Res. 216: 229237.

Barber, P. C. (1981b) Regeneration of vomeronasal nerves into the olfactory bulb in the mouse. Brain Res. 216: 239-251.

Bernhardt, R., and A. Matus (1984) Light and electron microscopic studies of the distribution of microtubule-associated protein 2 in rat brain: A difference between the dendritic and axonal cytoskeletons. J. Comp. Neurol. 226: 203-221.

Bernhardt, R., G. Huber, and A. Matus (1985) Differences in the developmental patterns of three microtubule-associated proteins in the rat ccrcbcllum. J. Neurosci. 4: 977-991.

Binder, L. I., A. Frankfurter, H. Kim, A. Caceres, M. R. Payne, and L. I. Rebhun (1984) Heterogeneity of microtubule-associated protein 2 during rat brain development. Proc. Natl. Acad. Sci. USA 81: 56135617.

Binder, L. I., A. Frankfurter, and L. I. Rebhun (1985) The distribution of tau in the mammalian central nervous system. J. Cell Biol. 101: $1371-1378$.

Bloom, G. S., F. C. Luca, and R. B. Vallee (1985) Microtubule-associated protein 1B: Identification of a major component of the neuronal cytoskeleton. Proc. Natl. Acad. Sci. USA 82: 5404-5408.

Brugg, B., and A. Matus (1988) PC.12 cells express juvenile microtubule-associated proteins during NGF-induced neurite outgrowth. J. Cell Biol. 107: 643-650.

Burgoyne, R. D., and R. Cumming (1984) Ontogeny of microtubuleassociated protein 2 in rat cerebellum: Differential expression of the adult doublet polypeptide. Neuroscience 11: 157-167.

Busciglio, J., A. Ferreira, O. Steward, and A. Caceres (1987) An immunocytochemical and biochemical study of the microtubule-asso- ciated protein, tau, during post-lesion afferent reorganization in the hippocampus of adult rat. Brain Res. 419: 244-252.

Caceres, A., L. I. Binder, M. R. Payne, P. Bender, L. Rebhun, and O. Steward (1984) Differential subcellular localization of tubulin and the microtubule-associated protein MAP2 in brain tissue as revealed by immunohistochemistry with monoclonal hybridoma antibodies. J. Neurosci. 4: 394-410.

Calvert, R. A., and B. H. Anderton (1985) A microtubule-associated protein (MAP1) which is expressed at elevated levels during development in rat cerebellum. EMBO J. 4: 1171-1176.

Davis, L. G., M. D. Dibner, and J. F. Battey (1986) Basic Methods in Molecular Biology. Elsevier, New York.

De Camilli, P., P. E. Miller, F. Navone, W. E. Theurkauf, and R. B. Vallee (1984) Distribution of microtubule-associated protein 2 in the nervous system of the rat studied by immunofluorescence. Neuroscience $11: 817-846$.

Drubin, D., S. Kobayashi, D. Kellog, and M. Kirschner (1988) Regulation of microtubule protein levels during cellular morphogenesis in nerve growth factor-treated PC12 cells. J. Cell Biol. 106: 15831591.

Faivre, C., Ch. Legrand, and A. Rabie (1985) The microtubule apparatus of cerebellar Purkinje cells during postnatal development of the rat: The density and cold-stability of microtubules increase with age and are sensitive to thyroid hormone. Int. J. Dev. Neurosci. 3: 559-565.

Feinberg, A. P., and B. Vogelstein (1984) A technique for radiolabelling DNA restriction endonuclease fragments to high specific activity. Anal. Biochem. 137: 266-267.

Francon, J., A. M. Lennon, A. Fellous, A. Mareck, M. Pierre, and J. Nunez (1982) Heterogeneity of microtubule-associated proteins and brain development. Eur. J. Biochem. 129: 465-471.

Garner, C. C., and A. Matus (1988) Different forms of microtubuleassociated protein 2 (MAP2) are encoded by separate mRNA transcripts. J. Cell Biol. 106: 779-784.

Garner, C. C., B. Brugg, and A. Matus (1988) A $70 \mathrm{kDa}$ microtubuleassociated protein 2 (MAP2c), related to MAP2. J. Neurochem. 50: 609-615.

Garner, C. C., A. Matus, B. Anderton, and R. Calvert (1989) Microtubule-associated proteins MAP5 and MAP1x: Closely related components of the neuronal cytoskeleton with different cytoplasmic distributions in the developing brain. Mol. Brain Res. 5: 85-92.

Graziadei, P. P. C., and G. A. Monti-Graziadei (1979) Neurogenesis and neuron regeneration in the olfactory system of mammals. I. Morphological aspects of differentiation and structural organization of the olfactory sensory neurons. J. Neurocytol. $8: 1-18$.

Greene, L. A., R. K. H. Liem, and M. L. Shelanski (1983) Regulation of high molecular weight microtubule-associated protein in PC1 2 cells by nerve growth factor. J. Cell Biol. 96: 76-83.

Hawkes, R., E. Niday, and J. Gordon (1982) A dot-immunobinding assay for monoclonal and other antibodies. Anal. Biochem. 119: 142147.

Heimann, R., M. L. Shelanski, and R. K. Liem (1985) Microtubuleassociated proteins bind specifically to the $70-\mathrm{kDa}$ neurofilament protein. J. Cell Biol. 260: 12160-12166.

Huber, G., and A. Matus (1984) Differences in the cellular distributions of two microtubule-associated proteins, MAP1 and MAP2, in the rat brain. J. Neurosci. 4: 151-160.

Julien, J.-P., and W. E. Mushynski (1982) Multiple phosphorylation sites in mammalian neurofilament polypeptides. J. Biol Chem. 257: 10467-10470.

Karr, L. T., H. D. White, and D. L. Purish (1979) Characterization of brain microtubule proteins prepared by selective removal of mitochondrial and synaptosomal components. J. Biol. Chem. 254: 61076111.

Laemmli, U. K. (1970) Cleavage of structural proteins during the assembly of the head of bacteriophage T4. Nature 227: 680-685.

Lennon, A. M., J. Francon, A. Fellous, and J. Nunez (1980) Rat, mouse, and guinea pig brain development and microtubule assembly. J. Neurochem. 35: 804-813.

Letterier, J. F., R. Liem, and M. Shelanski (1982) Interactions between neurofilaments and microtubule-associated protcins: A possible mechanism for intra-organellar bridging. J. Cell Biol. 95: 982-986.

Lindwall, G., and R. D. Cole (1984) Phosphorylation affects the ability of tau protein to promote microtubule assembly. J. Biol. Chem. 259: 5301-5305. 
Matus, A. (1988) Microtubule-associated proteins and neuronal morphogenesis. Annu. Rev. Neurosci. 11: 29-44.

Matus, A., R. P. Tucker, and C. Viereck (1990) Microtubule-associated proteins in cerebellar morphogenesis. In Neurobiology of the Cerebellar Systems, R. Llinas and C. Sotelo, eds., Oxford U. P., New York (in press).

Miragall, F., G. Kadmon, M. Husmann, and M. Schachner (1988) Expression of cell adhesion molecules in the olfactory system of the adult mouse: Presence of the embryonic form of N-CAM. Dev. Biol. 129: $516-531$.

Murthy, A. S., and M. Flavin (1983) Microtubule assembly using microtubule-associated protein MAP-2 prepared in defined states of phosphorylation with protein kinase and phosphatase. Eur. J. Biochem. 137: 37-46.

Nishida, E., T. Kuwaki, and H. Sakai (1981) Phosphorylation of microtubule-associated proteins (MAPs) and $\mathrm{pH}$ of the medium control interaction between MAPs and actin filaments. J. Biochem. Tokyo 90: 575-578.

Nunez, J. (1986) Differential expression of microtubule components during brain development. Dev. Neurosci. 8: 125-141.

Papasozomenos, S. Ch., and L. I. Binder (1987) Phosphorylation determines two distinct species of tau in the central nervous system. Cell Motil. Cytoskel. 8: 210-226.

Pinching, A. J., and T. P. S. Powell. (1971) The neuropil of the glomeruli of the olfactory bulb. J. Cell Sci. 9: 347-377.

Reinhard, E., R. Meier, W. Halfter, G. Rovelli, and D. Monard (1988) Detection of glia-derived nexin in the olfactory system of the rat. Neuron 1: 387-394.

Riederer, B., and A. Matus (1985) Differential expression of distinct microtubule-associated proteins during brain development. Proc. Natl. Acad. Sci. USA 82: 6006-6009.

Riederer, B., R. Cohen, and A. Matus (1986) MAP5: A novel brain microtubule-associated protein under strong developmental regulation. J. Neurocytol. 15: 763-775.

Schwob, J. E., N. B. Farber, and D. I. Gottlieb (1986) Neurons of the olfactory epithelium in adult rats contain vimentin. J. Neurosci. 6 : 208-217.
Seldon, S. C., and T. D. Pollard (1983) Phosphorylation of microtubule-associated proteins regulates their interaction with actin filaments. J. Cell Biol. 258: 7064-7071.

Stallcup, W. L. L. Beasley, and J. M. Levine (1985) Antibody against nerve growth factor-inducible large external (NILE) glycoprotein labels nerve fiber tracts in the developing rat nervous system. J. Neurosci. 4: 1090-1101.

Towbin, H., T. Staehelin, and J. Gordon (1979) Electrophoretic transfer of protein from polyacrylamide gels to nitrocellulose sheets: Procedure and some application. Proc. Natl. Acad. Sci. USA 76: 43504354.

Tucker, R. P., and A. Matus (1987) The molecular form and distribution of two developmentally regulated microtubule-associated proteins (MAP2 and MAP5) during the morphogenesis of the avian retina. Development 101: 535-546.

Tucker, R. P., L. I. Binder, and A. Matus (1988a) Neuronal microtubule-associated proteins in the embryonic spinal cord. J. Comp. Neurol. 271: 44-55.

Tucker, R. P., L. I. Binder, and A. Matus (1988b) Differential localization of the high- and low-molecular weight variants of MAP2 in the developing retina. Dev. Brain Res. 38: 313-318.

Tucker, R. P., L. I. Binder, C. Viereck, B. A. Hemmings, and A. Matus (1988c) The sequential appearance of low- and high-molecular weight forms of MAP2 in the developing cerebellum. J. Neurosci. 8: 45034515 .

Viereck, C., R. P. Tucker, L. I. Binder, and A. Matus (1988) Phylogenetic conservation of brain microtubule-associated proteins MAP2 and tau. Neuroscience 26: 893-904.

Wallis, I., L. Ellis, K. Suh, and K. H. Pfenninger (1985) Immunolocalization of a neuronal growth-dependent membrane glycoprotein J. Cell Biol. 101: 1990-1998.

Wilson, K. C. P., and G. Raisman (1980) Age-related changes in the neurosensory epithelium of the mouse vomeronasal organ: Extended period of postnatal growth in size and evidence for rapid cell turnover in the adult. Brain Res. 185: 103-113. 